Николаев Андрей Сергеевич

аспирант факультета технологического менеджмента и инноваций Санкт-Петербургского национального исследовательского университета информационных технологий, механики и оптики

\section{ОСОБЕННОСТИ УПРАВЛЕНИЯ ИННОВАЦИОННОЙ ДЕЯТЕЛЬНОСТЬЮ ФАРМАЦЕВТИЧЕСКОГО ПРЕДПРИЯТИЯ НА ОСНОВЕ ПАТЕНТНЫХ ЛАНДШАФТОВ}

Аннотация:

В статье описаны принципы построения системы управления инновационной деятельностью российского фармацевтического предприятия на основе создания патентных ландшафтов. Последние представляют собой комплексный результат патентного почска, отражающий текущее положение организации на рынке с учетом действующего портфеля нематериальных активов. В работе отмечается необходимость пере хода фармацевтических компаний к комплексной оценке инновационных проектов в целях принятия решений о выведении нового препарата на рынок. Автор предлагает использовать патентные ландшафты в качестве ядра системы управления интеллектуальной собственностью фармацевтической организации для создания информационной основы для запуска процессов по разработке оригинальных препаратов, что позволит перевести отечественную фармацевтиче скую промышленность на качественно новый уровень. В качестве доказательной базы используется практический опыт автора.

Ключевые слова:

патентные ландшафты, патентная аналитика, интеллектуальная собственность, управление инновациями, фармацевтическая промышленность, инновационные риски, минимизация риска, "Фарма 2030».
Nikolaev Andrey Sergeevich

PhD student, School of Technology Management and Innovation, Saint Petersburg National Research University of Information Technologies, Mechanics and Optics

\section{THE ASPECTS OF INNOVATION MANAGEMENT OF A PHARMACEUTICAL COMPANY BASED ON PATENT LANDSCAPES}

Summary:

The study describes the principles of building the innovation management system of a Russian pharmaceutical company based on the creation of patent landscapes. Patent landscapes are a comprehensive result of a patent search that demonstrates the current market position of a company in the context of the current portfolio of intangible assets. The study notes that it is necessary for pharmaceutical companies to start to carry out a comprehensive assessment of innovative projects to make a decision and launch a new drug. The author proposes to use patent landscapes as the core of a pharmaceutical company's intellectual property management system to create an information platform for original drugs development. It makes it possible to raise the level of the Russian pharmaceutical industry. The author's practical experience is used as an evidence base.

Фармацевтическая промышленность является стратегически важной отраслью наукоемкого производства, поскольку обеспечение населения качественными и доступными лекарственными препаратами выступает одним из элементов национальной безопасности страны. Кроме того, производство лекарств остается сложным многоэтапным процессом, а инвестиции в данной области имеют больший срок окупаемости из-за необходимости проведения ряда доклинических, клинических и иных дополнительных испытаний, длительность которых составляет в среднем около 5 лет. Другой особенностью отрасли становится постоянное расширение инновационного горизонта за счет результатов научно-технического прогресса. Инновационная деятельность служит одним из ключевых источников развития компаний, а инновации становятся не только показателем их надежности и современности, но и условием выживания на рынке [1].

Высокая стоимость инноваций в фармацевтике стала одной из причин возникновения двух магистральных инновационных трендов. Так, компании разделяют все инновационные лекарственные препараты на оригинальные, созданные впервые и не имевшие аналогов, направленные на лечение новых заболеваний или предлагающие новые подходы к терапии, а также воспроизведенные лекарственные препараты (дженерики и биоаналоги). В отрасли действуют жесткие патентные стратегии, главная задача которых сводится к формированию таких условий защиты разработок, при которых нарушение прав владельца патента для конкурентов будет за- 
труднено до той степени, что затраты будут сопоставимы с созданием нового оригинального препарата. Для выведения на рынок препарат должен пройти длительные исследования, призванные подтвердить безопасность и эффективность лекарства, поэтому появляется проблема, когда патент на изобретение уже получен, информация о препарате доступна конкурентам, а сам препарат еще не выпущен на рынок. При этом лидирующие предприятия начинают использовать все возможные средства продления патентной охраны препарата, иначе по истечении максимально возможных 25 лет разработка перейдет в общественное достояние, а с этого момента на основании оригинального препарата можно создавать воспроизведенные - дженерики - без опасности нарушений действующих патентов. Таким образом, перед современными фрармацевтическими компаниями встает рациональный выбор: производить оригинальные препараты или дженерики. Наблюдается необходимость в качественных инструментах оценки инновационных рисков, которые смогут подготовить надежную информационную базу для поиска ответов на вопросы: «В какой области следует создавать оригинальный препарат?»; «На основании каких препаратов нужно создавать дженерик?»; «Какими ресурсами мы обладаем для достижения поставленных целей?»[2].

В рамках настоящего исследования проведен анализ методик управления инновационной деятельностью на трех российских фрармацевтических предприятиях. Автор статьи является сотрудником патентного отдела одной из рассматриваемых компаний, что позволило ознакомиться с методами управления инновациями при реализации программ обмена опытом. Фирма А - инновационный лидер на рынке, создает решения в перспективной области компьютерного дизайна лекарственных препаратов. Компания Б имеет в портфеле как собственные оригинальные препараты, так и дженериковые и выступает лидером в своем сегменте рынка, но количество дженериков превалирует - 10 препаратов против 3. Предприятие В концентрируется на производстве безрецептурных дженериков, которые пользуются спросом у потребителей. Каждая из перечисленных организаций применяет дженерики как средство получения прибыли, которая может служить в качестве инвестиций в новые проекты.

Компании Б и В на основании маркетинговых исследований рынка и проверки патентной чистоты препаратов инвестируют в другие дженерики в целях расширения продуктового портфеля. Фирма Б также вкладывает часть средств в собственные разработки, используя дженерики как защитный механизм, позволяющий нивелировать расходы, связанные с проведением длительных испытаний. Предприятие А также применяет дженерики в качестве источника фринансирования будущих разработок, однако при выборе направлений исследований опирается на результаты анализа патентных данных.

Оценка управленческих практик в сфере выбора направлений инновационного развития российских фармацевтических компаний с учетом личного опыта исследователя позволила установить приверженность компаний к реализации стратегии расширения продуктового портфеля в целях занятия выбранных рыночных ниш. Информационной основой решений служит маркетинговый анализ, цель которого состоит в выявлении спроса на определенные препараты, прогнозирование спроса на препарат и расчет того объема рынка, который сможет занять создаваемый препарат. Подобный метод формирует достоверное представление и дает возможность принимать качественные управленческие решения, однако фокусируется на уже разработанных рынках, а значит, несет в себе дженериковый подход, при котором выбирается препарат, способный принести прибыль в среднесрочной перспективе.

Этап анализа рынков проводится без использования патентной информации, а патентный поиск осуществляется на последней стадии подготовительного процесса для определения сроков окончания патента на оригинальный препарат. Так, предприятия, выбрав перспективный дженерик, получают возможность за три года до окончания действия патентной защиты занять проактивную позицию и практически одновременно с окончанием правовой охраны оригинального препарата вывести на рынок дженерик, что особенно важно для препаратов, подпадающих под действие программ государственных закупок. Таким образом, патентная информация применяется лишь для поиска слабых мест в патентной защите оригинальных препаратов для начала производства дженериков.

Выпуск дженериков российскими компаниями стал одним из важных следствий реализации стратегии развития отечественной фармацевтической промышленности до 2020 г., именуемой сокращенно «Фарма 2020». Государственная поддержка производства дженериков призвана снизить зависимость отечественного фрармацевтического рынка от зарубежных лекарственных препаратов. Фармацевтические предприятия наладили в стране собственный выпуск или стали площадкой для локализации производственных процессов иностранных фармацевтических фрирм, осуществляющих на территории создание готовых лекарственных форм, например таблетирова- 
ние, фрасовку и предпродажную подготовку. Подобная модель развития отечественной фармацевтики привела к выполнению задач стратегии «Фарма 2020» в части обеспечения населения отечественными лекарственными препаратами, однако создала условия, при которых российские фрармацевтические предприятия выбирают дженериковую стратегию как наиболее понятную. В частности, по данным DSM Group на июнь 2019 г., дженерики занимают значительную долю отечественного фармацевтического рынка - 62,7 \% в стоимостном выражении и 84,4 \% в натуральном [3]. С течением времени дженериков в рыночной нише становится все больше, а значит, увеличивается конкуренция, в то время как оригинальный препарат при выборе грамотной патентной стратегии позволит удержать лидерство в технологиях.

Для перехода от импортозамещающей дженериковой стратегии к ориентации на экспорт оригинальных лекарственных препаратов необходима система управления инновациями предприятия, основными принципами которой станут внедрение патентных ландшафтов в регулярную управленческую практику как инструмента превентивного управления инновационными рисками; комплексная оценка всех возможностей и угроз при создании лекарственного препарата с помощью патентных ландшафтов; постоянное обновление ключевых показателей патентных ландшафтов для мониторинга внешней среды и оценки силы патентного портфеля компании; формирование центров управления инновациями на базе интеграции в единый совещательный орган отделов планирования и развития бизнеса, маркетинга, управления интеллектуальной собственностью, а также научно-исследовательских подразделений компании в единый инновационный центр. Описанная система предполагает, что инициатором инноваций может стать каждый из ее указанных участников, что позволит расширить процесс генерации инноваций в организации. Идейный ландшафт фрирмы будет дополняться данными по трендам патентования в этой области, а также прогнозами по географии охвата инновации в настоящее время [4]. Так возникает внутреннее идейное пространство - важный инновационный ресурс, который даст возможность компании повысить эффективность управления нематериальными активами (рисунок 1).

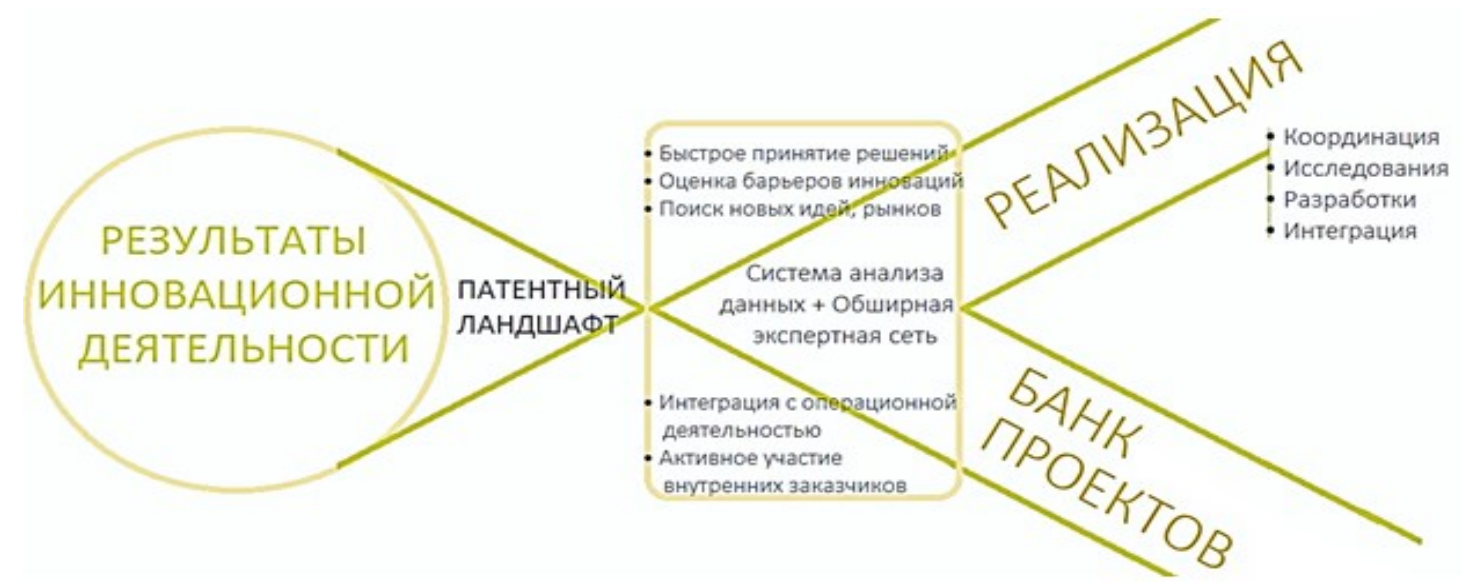

Рисунок 1 - Авторская модель системы управления инновациями на фармацевтическом предприятии на основе патентных ландшафтов

Предложенная модель ориентирована на опережающее развитие и может быть реализована в компаниях А и Б. Также для предприятий предлагается построение двух уровней патентных ландшафтов - внутреннего и внешнего. На первом анализируются идеи внутри предприятия и перспективы их дальнейшей реализации с учетом возможностей и ресурсных ограничений фирмы, а также действий конкурентов. Это позволит организации перейти к следующему этапу планирования инновационного продукта - сужению предметной области для построения ландшафта: от заболевания, включающего в себя множество форм и подвидов, к более частным аспектам с учетом доступности технологии производства, коммерческих ограничений (поставщиков необходимого сырья, каналов сбыта), правовых ограничений (параллельного импорта), а также ряда маркетинговых рамок, связанных с готовностью потребителей к какой-либо прорывной инновации, чье появление в фармацевтике вполне возможно при разработке препарата для лечения заболеваний, по которым ранее не существовало эффективных методов терапии.

Кроме того, в рамках системы управления инновациями в фармацевтических компаниях предлагается создание внутренних цифровых реестров, включающих в себя сведения как о защищенных объектах интеллектуальной собственности, так и о разработках, которые пока остаются под охраной режима коммерческой тайны. Цифровые реестры позволят контролировать 
сроки действия патентов в портфеле фрирмы. При выполнении исследовательских работ в интересах предприятия Б была проведена систематизация патентного портфеля, а также сформированы рекомендации по повышению эфффективности управления активами. Электронный реестр объектов интеллектуальной собственности с автоматизированным расчетом силы патента можно рассматривать как один из вариантов внутреннего патентного ландшафта.

Таким образом, в результате исследования можно сформулировать следующие выводы.

1. Проведена работа по адаптации методики управления инновационной деятельностью на основе построения патентных ландшафртов с учетом специфики фрармацевтической отрасли. Сформулирована концепция управления инновационной деятельностью фрармацевтического предприятия, ядром которой являются патентные ландшафты.

2. Создание системы управления инновациями фармацевтической отрасли с использованием патентных ландшафттов позволит российским компаниям реализовать собственный потенциал в сфере разработки оригинальных фрармацевтических препаратов. Предложенная система внутренних и внешних патентных ландшафтов даст возможность создавать инновации на основании выявленных потребностей рынка с учетом собственных ресурсов организации, в том числе уже имеющихся разработок.

3. Внедрение предлагаемой системы управления инновациями позволит компаниям успешно перейти к реализации стратегии «Фарма 2030», целью которой является переход от производства дженериков к созданию оригинальных препаратов с возможностью выведения на международный рынок [5].

4. Сфрормированные предложения были приняты к реализации только в одной из трех исследуемых компаний, что является свидетельством необходимости дальнейшей популяризации возможностей патентной аналитики в рамках разработки оригинальных препаратов.

\section{Ссылки:}

1. Михайлова М.В. Фармацевтическая промышленность в России: финансово-экономическое состояние и перспективы развития // Актуальные проблемы современной финансовой науки. М., 2017. С. 231-235.

2. Насонова К.В. Продление срока действия патента на лекарственное средство [Электронный ресурс] // Коллегиальные чтения - 2019. Презентации докладов. URL: http://spbkpp.org/wp-content/uploads/2019/07/09_Nasonova.pdf (дата обращения: 04.09.2019).

3. Фармацевтический рынок России. Июнь 2019 [Электронный ресурс] : аналитический отчет // DSM Group. 2019. URL: https://dsm.ru/docs/analytics/june 2019 pharmacy analysis.pdf (дата обращения: 04.09.2019).

4. Trippe A. Guidelines for Preparing Patent Landscape Reports [Электронный ресурс]. 131 р. // World Intellectual Property Organization. 2015. URL: https://www.wipo.int/edocs/pubdocs/en/wipo_pub_946.pdf (дата обращения: 04.09.2019).

5. Стратегия развития фармацевтической промышленности РФ на период до 2030 г. [Электронный ресурс] : проект распоряжения Правительства РФ // Управление : государственная автоматизированная информационная система. 2018. URL: http://gasu.gov.ru/stratpassport (дата обращения: 04.09.2019).

\section{References:}

Mikhailova, MV 2017, 'The Pharmaceutical Industry in Russia: Financial and Economic Status and Development Prospects', Aktual'nyye problemy sovremennoy finansovoy nauki, Moscow, pp. 231-235, (in Russian)

Nasonova, KV 2019, 'Pharmaceutical Patent Term Extension', Kollegial'nye chteniya - 2019. Prezentatsii dokladov, viewed 04 September 2019, <http://spbkpp.org/wp-content/uploads/2019/07/09_Nasonova.pdf>, (in Russian).

Trippe, A 2015, 'Guidelines for Preparing Patent Landscape Reports', World Intellectual Property Organization, 131 p., viewed 04 September 2019, <https://www.wipo.int/edocs/pubdocs/en/wipo_pub_946.pdf>. 